\title{
Development and psychometric evaluation of a new patient -reported outcome measure for stroke self -management: The Southampton Stroke Self - Management Questionnaire (SSSMQ)
}

\author{
Emma J Boger ${ }^{1 *}$, Matthew Hankins ${ }^{2}$, Sara H Demain ${ }^{1}$ and Susan M Latter ${ }^{1}$
}

\begin{abstract}
Background: Self-management is important to the recovery and quality of life of people following stroke. Many interventions to support self-management following stroke have been developed, however to date no reliable and valid outcome measure exists to support their evaluation. This study outlines the development and preliminary investigation of the psychometric performance of a newly developed patient-reported outcome measure (PROM) of self-management competency following stroke; the Southampton Stroke Self-Management Questionnaire (SSSMQ).

Methods: A convenience sample of 87 people who had had a stroke completed responses to the SSSMQ, the Stroke Self-Efficacy Questionnaire and the Stroke Impact Scale. Scaling properties were assessed using Mokken Scale Analysis. Reliability and construct validity were assessed using intra-class correlation coefficient (ICC), Mokken and Cronbach's reliability coefficients and Spearman rank order correlations with relevant measures.

Results: Mokken scaling refined the SSSMQ to 28 scalable items. Internal consistency reliability (Mokken $r=0.89$ ) and test-retest reliability (ICC $=0.928$ ) were excellent. Hypotheses of expected correlations with additional measures held, demonstrating good evidence for construct validity.

Conclusions: Early findings suggest the Southampton Stroke Self-Management Questionnaire is a reliable and valid scale of self-management competency. The SSSMQ represents a potentially valid PROM for the evaluation of self-management following stroke.
\end{abstract}

Keywords: Stroke, Self-management, PROM development, Non-parametric item response theory, Reliability and validity

\section{Background}

Stroke is a major cause of death and disability worldwide [1] with potential long-term impact for the individual, such as social isolation [2, 3], long-term depression and anxiety $[4,5]$ and increased physical impairment [6]. Recovery following stroke is complex and multidimensional, encompassing bio-medical, psychological and sociological elements $[7,8]$. Engagement in selfmanagement practices by individuals with long-term conditions has been suggested as key to promoting

\footnotetext{
* Correspondence: e.j.boger@soton.ac.uk

${ }^{1}$ Faculty of Health Sciences, University of Southampton, Southampton SO17 1BJ, UK

Full list of author information is available at the end of the article
}

recovery [9] and is cited as a means of empowerment and a facilitator of improved health outcomes [10, 11]. Self-management, defined as those activities (examples include eating well, exercising, taking medicines, monitoring and managing symptoms) people with a longterm health condition do to stay well and maintain good physical and emotional well-being [12] is not new to western health care. Since the development of the United States based chronic disease self-management programme [13] and subsequent adaption for other western health care settings [14-16], self-management has received growing attention as part of the management of people with long-term conditions $[17,18]$. 
Self-management interventions (SMIs) are designed to enable people to manage their health more effectively. Stroke SMIs often aim to modify attitudes and behaviours such as goal-setting and lifestyle changes [19, 20] requiring the development or enhancement of skills to self-manage effectively. However, what elements should be included in stroke SMIs remains inconclusive [21]. Patient-Reported Outcome Measures (PROMs) measure how patients function or feel in relation to their health condition, and are recognised as fundamental health outcomes in their own right [22]. A systematic review identified that stroke SMIs have been evaluated by measurement of heterogeneous concepts such as physical function, quality of life, self-efficacy, satisfaction and mood (Boger et al. 2013). The review identified 43 different outcome measures, of which 21 measures (49 \%) demonstrated some psychometric properties in stroke populations. This indicates a lack of consensus regarding the appropriate measures to assist evaluation of stroke SMIs, and/or a recognition that selfmanagement embraces a range of differing concepts. The majority of measures scored either 'fair' or 'poor' according to the COSMIN quality criteria [23], possessing limited psychometric validity. For example, the Barthel Index [24] a measure of physical function, scored poorly due its lack of engagement with users in development and the Functional Independence Measure [25] a measure of physical and cognitive disability, scored 'fair' for internal consistency.

No outcome measure exists to adequately measure stroke self-management behaviours, attitudes or skills as discrete concepts, or from the patients' perspective (Boger et al., 2013). This study used non-parametric item response theory (IRT) to investigate the psychometric properties of a new patient-reported outcome measure of stroke self-management competency to help address this knowledge gap and enhance the evidence quality in terms of the effectiveness of SMIs.

\section{Aims}

To investigate the scale structure, reliability and evidence for validity of the Southampton Stroke SelfManagement Questionnaire (SSSMQ).

\section{Methods}

\section{Item elicitation}

Items for the SSSMQ were developed following two qualitative phases involving people who had experienced a stroke, to enhance content validity and ensure item relevance $[26,27]$. Five focus groups $(n=28)$ were first conducted to identify the factors which facilitate and hinder self-management following stroke, and to generate a preliminary item pool. The findings of this research have been reported elsewhere [28]. Cognitive interviewing, a technique to ensure items included in PROMs have precision and relevance to potential respondents (Willis, 2005), was then used to investigate the suitability, acceptability and interpretation of the item pool with an additional sample of people who had experienced stroke $(n=11)$. Preferences for response format were also investigated during cognitive interviewing. Participant's feedback was sought on three different response scales; the six-point scale was chosen based on the preferences of the sample.

44 items were presented for psychometric testing (Appendix 1: Table 4). Items were rated on a 6 point Likert-style (Always true $=6$, Always false $=1$ ), based on the preferences of the cognitive interview sample for response format. Reverse scoring was applied on some items $(3-5,7,9-13,22,24,26,28,34,41)$.

\section{Scale development}

\section{Sample}

A nationally recruited convenience sample was sought via advertisement on websites and newsletters of two UK-wide stroke charities, stroke support groups, selected from regions across the UK, and from a regional stroke research participant newsletter. Participants were community dwelling adults (18 years or over), who reported having at least one stroke not less than 3 months previously, who had been discharged from acute medical management and who could read English sufficiently to complete a questionnaire written in English. No upper age limits were applied. Participants were asked whether they had "ever taken part in a stroke or health education programme (run by health professionals or patient experts)": none reported that they had done so.

Two additional patient-report outcome measures were used to investigate construct validity; the Stroke Impact Scale version 3.0 (SIS) [29] and the Stroke Self-Efficacy Questionnaire (SSEQ) [30, 31]. The SIS is a measure of health status after stroke and consists of 59 items, entailing eight domains as follows: Strength; Hand function; ADL/IADL; Mobility; Communication; Emotion; Memory and thinking and Participation/Role function. Responders rate the level of difficulty pertaining to each item on a 5-point Likert response format, generating summative scores for each domain. Internal consistency reliability ranges from $\alpha=0.83-0.90$ [32]. We hypothesised that health status would be positively associated with self-management skills, attitudes and behaviours. Hence, higher scores within each domain of the SIS would correlate with higher scores on the SSSMQ.

At the time the study was conducted, the SSEQ consisted of a 13-item self-report scale measuring selfefficacy judgements in specific domains of functioning post stroke using a $0-10$ visual analogue response scale. Internal consistency reliability of the SSEQ is reported as $\alpha=0.90$ [30]. Following subsequent Rasch analysis 
[31], the SSEQ is thought to measure two distinct unidimensional constructs of self-management self-efficacy and activity self-efficacy, and be better suited to a fourpoint response scale. The SSEQ was selected to examine the hypothesis that stroke specific self-efficacy was positively associated with self-management skills, attitudes and behaviours. Hence higher scores on the SSEQ would correlate with higher scores on the SSSMQ.

Data regarding age, gender, length of time since most recent stroke, living situation and ethnicity were also collected via self-report.

Participants received an information sheet about the study and could opt to complete a paper (postage paid return envelope included), or an on-line version of the questionnaires (permission was gained from the authors of the SSEQ and SIS to convert them to an online format) using survey software (www.smartsurvey.co.uk). To avoid over-burdening participants during test-retest reliability evaluation, participants who completed the first questionnaire were invited to opt into completing a repeat SSSMQ (repeat testing of the other measures was not deemed necessary as these already have proven reliability.). To avoid a potential bias from this group, a sub-sample of those who opted to complete a second SSSMQ were randomly selected, two weeks after first completion, using block randomisation. Test-retest participants were grouped consecutively into a 'block' of five participants and randomised as follows:

Block 1 - YYNNY Block 2 - YNYNY Block 3NNYYY

(Where, ' $\mathrm{Y}$ ' received second mailing, ' $\mathrm{N}$ ' did not receive second mailing).

Following the first 15 positive responders, the block allocation resumed at block 1, and repeated until close of recruitment.

\section{Data analysis}

Data were coded and entered into SPSS 21.0 (Statistical Package Program for Social Sciences; SPSS Inc., Chicago, IL, USA) for the analysis of descriptive statistics, investigation of reliability and for correlations with additional measures. Data were saved in a tab-delimited format for import into the Mokken Scaling Procedure (MSP) [33] and scale structure was investigated using the Automated Item Selection Procedure (AISP) for Mokken Scale Analysis (MSA) within the ' $R$ ' statistical package 'Mokken' [34]. The Mokken package was used to test for items which produce monotonically non-decreasing item characteristic curves. Using the MSP, a unidimensional scale is conventionally indicated by a Loevinger's coefficient $(\mathrm{H})>0.3$ [35]. Items violating monotone homogeneity were removed from the analysis until no further violations were present, ensuring a unidimensional scale.
The study received peer review and ethical and research governance approval prior to data collection commencing (University of Southampton, Faculty of Health Sciences Research Ethics committee, FoHS-2982). Following receipt of a participant information sheet, completion and return of the questionnaires via either mode indicated consent for participation in the study.

\section{Results}

During April -June 2013, 87 completed responses were received from a total of 95 returned questionnaires. Six (postal) incomplete responses were returned and were excluded from the analysis. The majority of responses were submitted via the online method (62\%). Response rate for those completing online responses was not calculated due to difficulties in accurately assessing how many people had viewed via this medium. The response rate for those returning paper versions was $62 \%$. Respondent characteristics are summarised in Table 1.

Conceivably, those who live with others may possess a greater level of dependency due to impairment, which may have a bearing on self-management ability. In this sample, one way analysis of variance (ANOVA) tests revealed that perceived level of recovery (as measured by the SIS) was not statistically different for those who lived alone ( mean $=64.0, \mathrm{SD}=26.4$ ) compared to those who lived with partners or family members (mean = $54.2, \quad \mathrm{SD}=21.8) \quad(p=0.06)$. Self-efficacy (Stroke Selfefficacy Questionnaire), was also not statistically significant between those who lived alone (mean 80.6, $\mathrm{SD}=$ $34)$ or with others (mean $=90.6, \mathrm{SD}=42.7)(p=0.376)$.

\section{Scale determination}

From the 44 items presented for scale determination, 12 items did not meet the criteria for a Mokken scale $(H>0.3)$ and were thus excluded from the Mokken analysis. The remaining 32 items possessed individual $H$ coefficients ranging from $0.96-0.39$, with an overall $H$ coefficient of 0.274 , indicating a borderline Mokken scale [36]. Using the Automated Item Selection Procedure (AISP) for MSA within $R$ statistical software package [34], threshold values were incrementally increased by .05 from $>.35->.5$ for the remaining 32 items.

Items remained as one scale at the $>0.35$ threshold, but split as thresholds increased. Items retained at the $>0.3,>0.35$ and $>0.4$ thresholds were re-examined. Four items worded similarly to items retained in the scale and sharing the same $H$ coefficient were removed, based on which item was best interpreted by potential users of the scale, informed by the cognitive interviewing data (appendix 1). Loevinger's coefficient $H$ for the resulting 28 -itemed scale was 0.353 , indicative of an acceptable Mokken scale. Figure 1 summarises the development phases. 
Table 1 Summary of sample characteristics

\begin{tabular}{|c|c|c|c|}
\hline \multicolumn{4}{|l|}{ Questionnaire } \\
\hline & SSSMQ $^{a}$ & SSEQ $^{a}$ & $\mathrm{SIS}^{\mathrm{a}}$ \\
\hline \multirow{2}{*}{$\begin{array}{l}\text { No. of complete responses (\% of } \\
\text { returned responses, } n=95 \text { ) }\end{array}$} & 87 & 83 & 74 \\
\hline & (92) & (87) & (78) \\
\hline Age range (years) & $(27-89)$ & $(27-89)$ & $(27-89)$ \\
\hline Mean & 58.40 & 59.20 & 57.99 \\
\hline [SD] & {$[14.74]$} & {$[14.74]$} & {$[14.66]$} \\
\hline Male gender (\%) & $40(51)$ & $43(52)$ & $37(50)$ \\
\hline Mean months since & 55 & 59 & 51 \\
\hline stroke [SD] & {$[63.36]$} & {$[63.82]$} & [56.29] \\
\hline range\# & 319\# & 319\# & 273\# \\
\hline \multicolumn{4}{|l|}{ Mode of completion } \\
\hline \multirow[t]{2}{*}{ Paper (\% of returned responses, $n=95$ ) } & 26 & 26 & 23 \\
\hline & (38) & (38) & (24) \\
\hline \multirow[t]{2}{*}{ Online (\% of returned responses, $n=95$ ) } & 69 & 69 & 72 \\
\hline & $(62)$ & $(62)$ & (76) \\
\hline \multicolumn{4}{|l|}{ Living situation } \\
\hline Live with others & 79 & 78 & 78 \\
\hline Live alone & 19 & 21 & 22 \\
\hline Unknown & 2 & 1 & 0 \\
\hline \multicolumn{4}{|l|}{ Ethnicity } \\
\hline White European ethnicity & 90 & 90 & 89 \\
\hline Non-white European ethnicity & 10 & 10 & 11 \\
\hline
\end{tabular}

aSSSMQ Southampton Self-Management Questionnaire, SSEQ Stroke Self-Efficacy Questionnaire, SIS Stroke Impact Scale

For investigation of reliability and validity, scores from the 28-itemed scale were used. Internal consistency reliability of the 28-itemed SSSMQ was examined using Cronbach's $\alpha$ [37] and Mokken's estimation of reliability, denoted $r$ [38]; values for $\alpha$ and $r$ were both 0.89 , indicating excellent internal consistency reliability [39]. MSA revealed the optimum number of items necessary to form a Mokken scale; there was no item redundancy. Test-retest reliability with a sub-sample of respondents ( $n=39,85 \%$ response rate) using the intraclass correlation coefficient was 0.928 indicating a high degree of reliability of the scale [40]. Mean time between the first and second test was 14.51 days (SD 5.8). Mean age of the test-retest sample was 60.13 years (SD 14.28); $64 \%$ of the sub-sample were male.

\section{Validity}

Total scores from the refined 28-item SSSMQ, were moderately and in most cases, significantly associated, in expected directions with variables hypothesised to influence stroke self-management attitudes, behaviours and skills (Table 2) providing preliminary evidence of convergent validity. Mean item scores were broadly centrally spread (Table 3). Mean total scores on the SSSMQ were statistically significant according to gender (female mean $=118.0, \mathrm{SD}=17.4$, versus male mean $=105, \mathrm{SD}$ $28.0 p=.020)$. Mean total SSSMQ scores were not statistically different for living circumstances (live alone mean $=112.6, \mathrm{SD}=16.7$, versus $113.8, \mathrm{SD}=21.3 p=.130$ ), nor age (Spearman's rho 0.063, $p=.576$ ).

\section{Discussion}

Mokken scale analysis revealed that the SSSMQ forms an acceptable unidimensional scale consisting of 28 items. Each item concerns a stroke self-management attitude, skill or behaviour. Collectively, based on the preliminary evidence of validity reported here, and subject to further validation work, the SSSMQ measures stroke self-management competency, the features an individual requires to be competent and capable of managing health and wellbeing following stroke.

Self-efficacy is the most commonly purported theoretical basis underpinning stroke self-management interventions [21, 41], whereby individuals with higher self-efficacy are thought better able to self-manage [42]. Self-efficacy is thought to mediate desirable health behaviours, such as, following a healthy lifestyle, taking prescription medication, that lead to improved motivation, treatment adherence, function and better clinical outcomes [43, 44]. Lower levels of self-efficacy are associated with lower mood and coping skills after stroke [45]. Consistent with this literature, SSSMQ scores correlated moderately with stroke self-efficacy, as measured by the SSEQ (Table 2) [46]. Higher self-efficacy scores were associated with increased SSSMQ scores and thus more successful selfmanagement behaviours, attitudes and skills.

Physical function is likely to affect individual's ability to perform tasks or strategies important to self-management $[47,48]$ along with social, emotional and cognitive factors. Total scores from the SSSMQ moderately correlated with the Strength; Hand function; ADL/IADL and Mobility domains of the SIS, although correlations with the Hand function and Strength domains were weak and not significant (Table 2). Further investigation of the relationship between self-management competency and physical function is therefore required.

Better self-management is thought to lead to improved well-being and mood [47], significant to recovery following stroke [48]. Low mood has been identified as a barrier to self-management $[49,50]$. Scores from the SSSMQ correlated positively with scores on the emotion domain of the SIS, suggesting that, individuals with lower mood, exhibit fewer desirable self-management behaviours and attitudes. Improved mood may augment self-management competency, or potentially vice versa. Positive correlations were also observed with the communication, memory and participation domains of the 


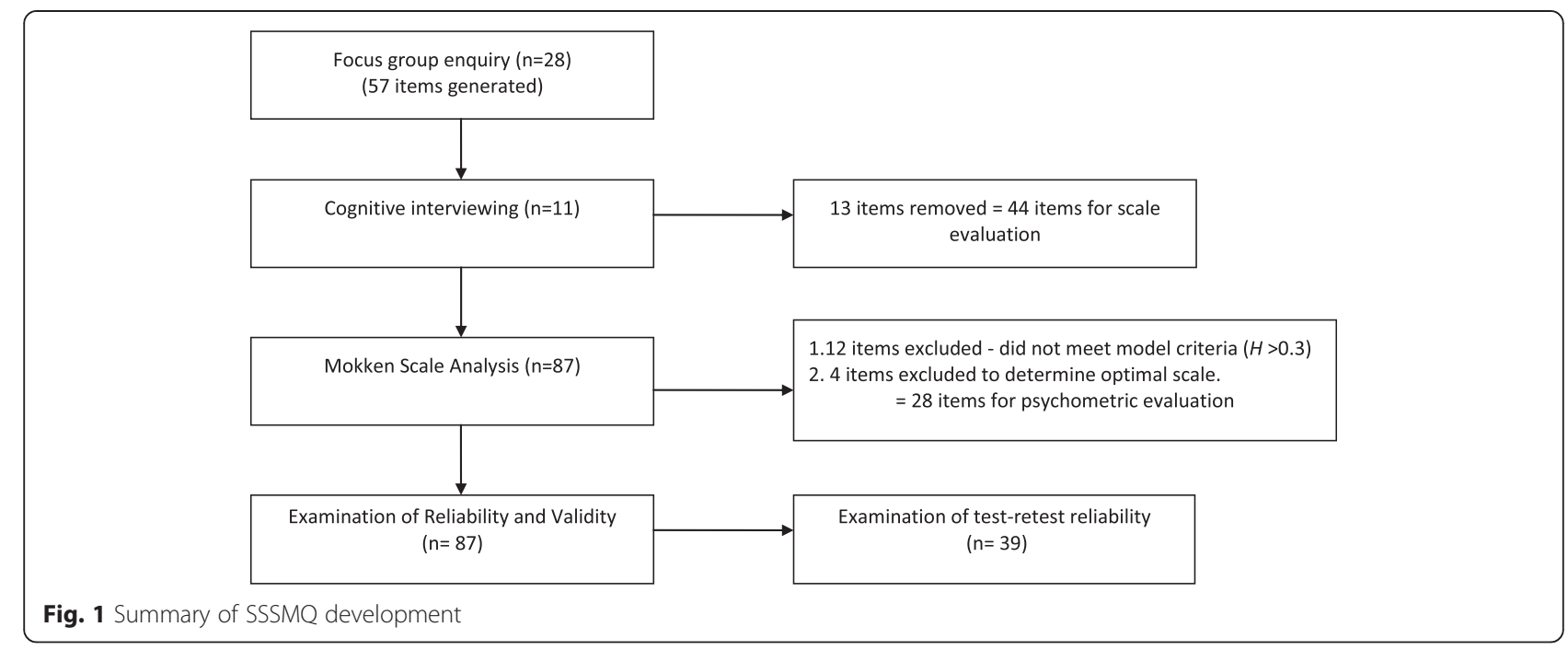

SIS, suggesting that these elements are important to self-management competency. Effective communication, which in stroke may be hindered by the presence of aphasia, is likely to enabled successful self-management [51] as navigating services and negotiating treatment strategies with professionals is key to self-management after stroke [52]. Improvement in the communication and participation domains of the SIS have been reported following a stroke self-management intervention [53], suggesting that effective self-management may have the potential to impact upon these domains.

Correlations with the SSSMQ and the SIS subscales provide preliminary evidence that successful selfmanagement is associated with improved quality of life. Conceptually, quality of life may be important to self-management; gaining more control over health and well-being can feasibly be considered to improve quality of life as people develop the coping skills to adjust to and manage their life post-stroke [47, 54]. Alternatively, those who possess a greater quality of life may be more likely to exhibit the skills necessary to self-manage competently.

A difference between gender and total SSSMQ scores was found. It is not surprising that gender might impact upon self-management attitudes, behaviours and skills, as women typically perform better in self-management interventions [55-57]. Total SSSMQ scores were not statistically associated with age or living circumstances as might have been expected given that previous research indicates that older adults and people who live alone, often find self-management more difficult $[50,58,59]$. Further development of the SSSMQ with additional psychometric testing is warranted to provide continuing evidence of discriminant validity.

Investigation of reliability demonstrates that the SSSMQ is an adequately stable measurement of stroke self-management competency. Internal consistency and test-retest reliability were excellent, but must be considered in light of the limitations of sample size.

The findings provide preliminary evidence of the reliability and validity of the SSSMQ. The predicted hypotheses made with regard to the relationship of scores from the SSSMQ and additional measures were borne out, suggesting that self-management competency is consistent with previously validated measures of stroke selfmanagement.

The optimal content, target outcomes, and mechanisms for change in stroke self-management interventions remain unclear [21, 60]. Measurement of an individuals' self-management competency, their attitudes towards self-management and relevant behaviours relies upon patient report. The SSSMQ potentially represents an instrument, grounded in the views of patients who have had experienced stroke, with which to evaluate the impact of interventions on stroke self-management competency following stroke.

There are several limitations of the study which are acknowledged. There are no definitive answers regarding

Table 2 Non-parametric correlation matrix of SSSMQ with additional measures

\begin{tabular}{|c|c|c|c|c|c|c|c|c|c|c|c|}
\hline & SSSMQ & SSEQ & Strength & $\begin{array}{l}\text { Hand } \\
\text { function }\end{array}$ & $\begin{array}{l}\text { ADL/ } \\
\text { IADL }\end{array}$ & Mobility & Communication & Emotion & $\begin{array}{l}\text { Memory \& } \\
\text { thinking }\end{array}$ & $\begin{array}{l}\text { Participation/role } \\
\text { function }\end{array}$ & $\begin{array}{l}0-100 \text { perceived } \\
\text { recovery } \sim\end{array}$ \\
\hline SSSMQ & & $.62^{\mathrm{a}}$ & .05 & .10 & $.24^{\mathrm{a}}$ & $.25^{\mathrm{a}}$ & $.38^{\mathrm{a}}$ & $.59^{a}$ & $.49^{\mathrm{a}}$ & $.36^{\mathrm{a}}$ & $.61^{a}$ \\
\hline
\end{tabular}

SSSMQ Southampton Stroke Self-Management Questionnaire $(n=87)$, SSEQ Stroke self-efficacy questionnaire $(n=83) \sim$ domain of the Stroke Impact Scale $(n=74)$ ${ }^{\mathrm{a} S i g n i f i c a n t}$ at the 0.01 level or lower 
Table 3 Item response summaries for SSSMQ ( $n=87){ }^{a}$ values rounded to 2 decimal places

\begin{tabular}{|c|c|c|c|}
\hline Item No & Item (r- denotes reverse score) & Mean $^{a}$ & $S D^{a}$ \\
\hline 1 & The effects of stroke mean that I cannot manage my recovery and health $(r)$ & 4.23 & 1.54 \\
\hline 2 & When things do not go well with my stroke, it is hard to stay positive $(r)$ & 3.04 & 1.45 \\
\hline 3 & It is not up to me to decide what the best ways to manage my stroke are $(r)$ & 2.72 & 1.19 \\
\hline 4 & The physical effects of stroke mean that I cannot manage my health as I would like (r) & 3.84 & 1.60 \\
\hline 5 & It is hard to be motivated to seek out solutions to problems relating to stroke (r) & 3.25 & 1.47 \\
\hline 6 & I am not sure what signs or symptoms might mean my health is changing $(r)$ & 4.27 & 1.56 \\
\hline 7 & My problems with communication mean that I cannot manage my health as I would like (r) & 3.92 & 1.68 \\
\hline 8 & Whatever I do, I will not improve my condition (r) & 4.50 & 1.15 \\
\hline 9 & The efforts I take to manage my health have a positive effect & 4.84 & 1.11 \\
\hline 10 & I find it difficult to tell health care professionals what I want or need $(r)$ & 4.83 & 1.27 \\
\hline 11 & I work out ways of managing my health following stroke together with health care professionals & 3.68 & 1.41 \\
\hline 12 & I am confident that health care professionals can answer my questions & 4.87 & 1.41 \\
\hline 13 & I feel confident at discussing any advice I don't understand with Doctors & 3.90 & 1.64 \\
\hline 14 & I feel confident at getting the information I need from health care professionals & 3.50 & 1.58 \\
\hline 15 & I know how to get help if I am concerned about my condition & 3.86 & 1.41 \\
\hline 16 & I plan my day so I can get things done without being tired & 4.18 & 1.41 \\
\hline 17 & I feel confident asking family members to help me do things important to my health & 4.08 & 1.29 \\
\hline 18 & I manage things related to stroke as well as other people with stroke & 3.19 & 1.64 \\
\hline 19 & I try different ways of doing things, until I find out what works for me & 4.24 & 1.66 \\
\hline 20 & Ideas and things that work for other people with stroke are helpful to my recovery & 4.27 & 1.62 \\
\hline 21 & I have useful information or advice to give to others regarding managing stroke & 3.83 & 1.57 \\
\hline 22 & I feel comfortable asking friends to help me do things important to my health & 4.12 & 1.48 \\
\hline 23 & I am concerned that the things I do to manage stroke, may cause harm if not guided by health care professionals $(r)$ & 4.58 & 1.09 \\
\hline 24 & I cannot alter what my healthcare professionals decide to do about my stroke $(r)$ & 4.67 & 1.03 \\
\hline 25 & My condition would improve if I received more professional help (r) & 4.55 & 1.23 \\
\hline 26 & Following advice from health care professionals is the only way I will manage stroke (r) & 4.10 & 1.50 \\
\hline 27 & I always follow professional advice about my health, to the letter (r) & 4.53 & 1.49 \\
\hline 28 & Constant professional advice would help me to manage my stroke $(r)$ & 4.56 & 1.03 \\
\hline
\end{tabular}

sample size requirements for IRT, however sample sizes of 100 are often adequate [61]. Therefore, the inferences drawn from the results must be considered in light of the relatively small sample size, and the possibility for type II errors in analysis. The average age of the UK stroke population is 75 years [62]. The sample in this UK based research was considerably younger at just over 58 years, which may in part explain the larger proportion of people who chose to take part on-line. Moreover, it is not possible to say if those taking part on-line had differing competency at using computers or different access to computers compared to a typical stroke population. The SSSMQ and study information were only available in English, which may have prevented or dissuaded those who do not have English as a first language from participating. Over $60 \%$ of the sample had a moderate communication impairment, according to scores from the communication domain $(<60)$ of the Stroke
Impact Scale. This is a strength of this study since people with communication impairment are often excluded from stroke research.

It is also acknowledged that a tension potentially exists between the items, which were inductively generated and considered important to potential users, and the criteria for discarding items that do not function well in a scale [63]. Nonetheless, Mokken scaling represents a measurement model with the least criteria in this respect and is the method most likely to resolve this tension in favour of retaining items $[64,65]$.

Further investigation of validity, including crosscultural applications, is necessary to provide further evidence of the psychometric properties of the SSSMQ with a larger, more diverse sample. Future studies should also include clinician/researcher obtained data regarding participants' level of impairment. This would aid judgements about the relationship between impairment and 
self-management competency. In this research, selection of outcome measures with which to investigate theoretical relationships with the SSSMQ focused on the prevailing theory of self-efficacy. Further exploration of construct validity with additional measures of concepts associated with self-management, such as health literacy, decision-making and the burden of self-management may further enhance the strength of the construct of self-management competency.

\section{Conclusions}

Mokken scale analysis revealed a 28-itemed outcome measure with acceptable scaling properties which can potentially be used to enhance evaluation of stroke selfmanagement interventions in research and clinical practice. Early findings suggest that the SSSMQ possesses excellent reliability and preliminary evidence of validity. Further investigation of validity and reliability of the SSSMQ is required. It follows that totalled item scores from the SSSMQ can potentially be used as an indicator of an individuals' level of self-management competency.

\section{Appendix 1}

Table 4 Full items presented for psychometric testing

\begin{tabular}{|c|c|}
\hline $\begin{array}{l}\text { Item } \\
\text { NO }\end{array}$ & Item \\
\hline 1 & $\begin{array}{l}\text { I regularly think about how I might change things to better } \\
\text { manage the consequences of stroke }\end{array}$ \\
\hline 2 & $\begin{array}{l}\text { I cannot rely solely on others to help me manage the } \\
\text { consequences of stroke }\end{array}$ \\
\hline 3 & Whatever I do, I will not improve my condition ( $r$ ) \\
\hline 4 & $\begin{array}{l}\text { When things do not go well with my stroke, it is hard to } \\
\text { stay positive (r) }\end{array}$ \\
\hline 5 & $\begin{array}{l}\text { I always follow professional advice about my health, to } \\
\text { the letter ( } r \text { ) }\end{array}$ \\
\hline 6 & $\begin{array}{l}\text { General self-care is important to me to stay as healthy as } \\
\text { possible }\end{array}$ \\
\hline 7 & $\begin{array}{l}\text { There is little point in trying new ways of managing the } \\
\text { consequences of stroke, as it will not change my condition (r) }\end{array}$ \\
\hline 8 & $\begin{array}{l}\text { I should make most of the decisions about how my stroke is } \\
\text { managed }\end{array}$ \\
\hline 9 & $\begin{array}{l}\text { It is hard to be motivated to seek out solutions to } \\
\text { problems relating to stroke }(r)\end{array}$ \\
\hline 10 & $\begin{array}{l}\text { It is difficult to stay motivated to do tasks or strategies } \\
\text { important to my recovery }(r)\end{array}$ \\
\hline 11 & $\begin{array}{l}\text { My condition would improve if I received more } \\
\text { professional help }(r)\end{array}$ \\
\hline 12 & $\begin{array}{l}\text { It is not up to me to decide what the best ways to } \\
\text { manage my stroke are }(r)\end{array}$ \\
\hline 13 & $\begin{array}{l}\text { I cannot alter what my healthcare professionals decide to } \\
\text { do about my stroke ( } r \text { ) }\end{array}$ \\
\hline
\end{tabular}

Table 4 Full items presented for psychometric testing (Continued)

\begin{tabular}{ll}
\hline 15 & I apply professional advice so it is relevant to my situation \\
16 & $\begin{array}{l}\text { I plan my day so I can get things done without being } \\
\text { tired }\end{array}$ \\
17 & I talk about any medication I am prescribed with healthcare \\
professionals & I find answers to problems about stroke without seeking \\
18 & professional advice \\
19 & I try different ways of doing things, until I find out what works
\end{tabular}

20 I know how to get help if I am concerned about my condition

21 The lifestyle choices that affect my health (for example, smoking, diet, alcohol, etc.) have changed since having a stroke

22 I am concerned that the things I do to manage stroke, may cause harm if not guided by health care professionals ( $r$ )

23 I feel confident at discussing any advice I don't understand with Doctors

24 I find it difficult to tell health care professionals what I want or need $(r)$

25 I always ask health care professionals to explain why / should follow their advice

26 Constant professional advice would help me to manage my stroke $(r)$

27 I am confident that health care professionals can answer my questions

Following advice from health care professionals is the only way I will manage stroke ( $r$ )

I work out ways of managing my health following stroke together with health care professionals

The physical effects of stroke mean that I cannot manage my health as I would like ( $r$ )

My problems with communication mean that I cannot manage my health as I would like ( $r$ )

The effects of stroke mean that I cannot control any aspect of my recovery and health

The effects of stroke mean that I cannot manage my recovery and health ( $r$ )

I am not sure what signs or symptoms might mean my health is changing $(r)$

I feel confident at getting the information I need from health care professionals

My efforts to manage the consequences of stroke turn out how I like

I am able to control my general health

The efforts I take to manage my health have a positive effect

I manage things related to stroke as well as other people with stroke

I have useful information or advice to give to others regarding managing stroke

1 I am reliant upon others to help me do things important to my health and well-being (this might for example, involve attending appointments, shopping for food, social activities) (r) 
Table 4 Full items presented for psychometric testing (Continued)

\section{$42 \quad$ I feel comfortable asking friends to help me do things important to my health \\ 43 I feel confident asking family members to help me do things important to my health \\ $44 \quad$ Ideas and things that work for other people with stroke are helpful to my recovery}

Items in BOLD text were retained following analysis $(r)=$ indicate items that are reverse scored Items in italics did not meet model criteria (H coefficients $<0.3$ )

\section{Competing interests}

There are no financial or non-financial competing interests associated with this research.

\section{Authors' contributions}

EB conceived the study design, performed data collection and analysis and drafted the manuscript. MH participated in study design, analysis and helped to draft the manuscript. SD and SL helped to conceive the study and contributed to interpretation of the data. All authors read and approved the final manuscript.

\section{Acknowledgements}

This research was supported by a Faculty of Health Sciences, University of Southampton Post-graduate research studentship award.

\section{Author details}

${ }^{1}$ Faculty of Health Sciences, University of Southampton, Southampton SO17 1BJ, UK. ${ }^{2}$ Real-World Evidence Solutions, IMS Health, London N1 9JY, UK.

Received: 11 March 2015 Accepted: 13 September 2015

Published online: 03 October 2015

\section{References}

1. Feigin V, Lawes C, Bennett D, Barker-Collo S, Parag V. Worldwide stroke incidence and early case fatality reported in 56 population-based studies: a systematic review. Lancet Neurol. 2009;8:355-69.

2. Reeves M, Prager M, Fang J, Stamplecoski M, Kapral M. Impact of living alone on the care and outcomes of patients with acute stroke. Stroke. 2014:45:3083-5.

3. Haley W, Roth D, Kissela B, Perkins M, Howard G. Quality of life after stroke: a prospective longitudinal study. Quality Of Life Research. 2011;20:799-806.

4. Ayerbe L, Ayis S, Wolfe C, Rudd A. Natural history, predictors and outcomes of depression after stroke: systematic review and meta-analysis. British Journal of Psychiatry. 2013;202:14-21.

5. Broomfield N, Scoular A, Welsh P, Walters M, Evans J. Poststroke anxiety is prevalent at the population level, especially among socially deprived and younger age community stroke survivors. Int I Stroke. 2015;10:897-902.

6. Mukherjee D, Patil C. Epidemiology and the global burden of stroke. World Neurosurg. 2011;76:S85-90

7. Jones F, Mandy A, Partridge C. Reasons for recovery after stroke: a perspective based on personal experience. Disability \& Rehabilitation. 2008;30:507-16.

8. Znaniecki F. The method of sociology. New York: Farrar \& Rinehart; 1934

9. de Ridder D, Geenen R, Kuijer R, van Middendorp H. Psychological adjustment to chronic disease. Lancet. 2008;372:246-55.

10. Battersby M, Lawn S, Pols R. Conceptualisation of self-management. In: Kralik D, Paterson B, Coates V, editors. Translating chronic illness research into practice. Chichester: John Wiley and Sons Ltd; 2010.

11. Kralik D, Koch T, Price K, Howard N. Chronic illness self-management: taking action to create order. J Clin Nurs. 2004;13:259-67.

12. Foundation $\mathrm{H}$. Evidence: helping people help themselves. A review of the evidence considering whether it is worthwhile to support self-management. London: The Health Foundation; 2011.

13. Lorig K. Self-management of chronic illness: a model for the future (self care and older adults). Generations. 1993;17:11-4.

14. The Flinders Program ${ }^{T M}$ care planning process [https://www.flinders.edu.au/ medicine/sites/fhbhru/self-management.cfm]
15. Franek J. Self-management support interventions for people with chronic disease: An Evidence based analysis (draft). In: Ontario Health Technology Assessment Series. Ontario, Canada: Health Quality Ontario; 2013. p. 1-61.

16. Kennedy A, Reeves D, Bower P, Lee V, Middleton E, Richardson G, et al. The effectiveness and cost effectiveness of a national lay-led self care support programme for patients with long-term conditions: a pragmatic randomised controlled trial. J Epidemiol Community Health. 2007:61:254-61.

17. The Scottish Government: Long Term Conditions Collaborative. Improving self management support. Edinburgh; 2009.

18. DoH. Common core principles to support self care: a guide to support implementation. London: Department of Health; 2008.

19. Hirsche R, Williams B, Jones A, Manns P. Chronic disease self-management for individuals with stroke, multiple sclerosis and spinal cord injury. Disabil Rehabil. 2011;33:1136-46.

20. Nour K, Laforest S, Gauvin L, Gignac M: Behavior change following a selfmanagement intervention for housebound older adults with arthritis: an experimental study. Int I Behav Nutr Phys Act 2006;3:12.

21. Lennon S, McKenna S, Jones F. Self-management programmes for people post stroke: a systematic review. Clin Rehabil. 2013;27:867-78.

22. Devlin N, Appleby J. Putting health outcomes at the heart of NHS decision making. London: King's Fund; 2010.

23. Mokkink L, Terwee C, Patrick D, Alonso J, Stratford P, Knol D, et al. The COSMIN checklist for assessing the methodological quality of studies on measurement properties of health status measurement instruments: an international Delphi study. Qual Life Res. 2010;19:539-49.

24. Mahoney F, Barthel D. Functional evaluation: the Barthel Index. Md Med J. 1965;14:61-5.

25. Dodds T, Martin D, Stolov W, Deyo R. A validation of the functional independence measurement and its performance among rehabilitation inpatients. Archives of Physical Medicine \& Rehabilitation. 1993;74:531-6.

26. Brod M, Tesler L, Christensen T. Qualitative research and content validity: developing best practices based on science and experience. Qual Life Res. 2009;18:1263-78

27. Lasch K, Marquis P, Vigneux M, Abetz L, Arnould B, Bayliss M, et al. PRO development: rigorous qualitative research as the crucial foundation. Qual Life Res. 2010;19:1087-96.

28. Boger E, Demain S, Latter S. Stroke self-management: A focus group study to identify the factors influencing self-management following stroke. Int J Nurs Stud. 2015;52:175-87.

29. Duncan P, Studenski S, Richards L, Gollub S, Lai S, Reker D, et al. Randomised clinical trial of therapeutic exercise in subacute stroke. Stroke. 2003;34:2173-80.

30. Jones F, Partridge C, Reid F. The Stroke Self-Efficacy Questionnaire: measuring individual confidence in functional performance after stroke. J Clin Nurs. 2008;17:244-52.

31. Riazi A, Aspden T, Jones F. Stroke Self-efficacy Questionnaire: A Raschrefined measure of confidence post stroke. J Rehabil Med. 2014;46:406-12.

32. Duncan P, Wallace D, Min Lai S, Johnson D, Embretson S, Jacobs Laster L. The stroke impact scale version 2.0: evaluation of reliability, validity, and sensitivity to change. Stroke. 1999:30:2131-40.

33. Molenaar I, Sijtsma K: MSP5 for Windows: A Program for Mokken Scale Analysis for Polytomous Items. Groningen: iec ProGAMMA; 2000.

34. van der Ark L: Mokken Scale Analysis in R. Journal of Statistical Software 2007;20(11):1-19.

35. van Schuur W. Ordinal item response theory. Mokken scale analysis. London: Sage; 2011.

36. Meijer R, Baneke J. Analyzing psychopathology items: a case for nonparametric item response theory modeling. Psychol Methods. 2004:9:354-68.

37. Cronbach L. Coefficient alpha and the internal structure of tests. Psychometrika. 1951;16:297-334.

38. Mokken R. A theory and procedure of scale analysis. Berlin, Germany: De Gruyter; 1971.

39. Streiner D, Norman G. Health Measurement Scales, a practical guide to their development and use. $4^{\text {th }}$ edition edn. Oxford: University Press; 2008.

40. de Vet $\mathrm{H}$, Terwee $\mathrm{C}$, Mokkink L, Knol D. Measurement in medicine. Cambridge: University Press; 2011.

41. Boger E, Demain S, Latter S: Self-management: A systematic review of outcome measures adopted in selfmanagement interventions for stroke. Disabil Rehabil. 2013;35(17):1415-28. 
42. Jones F, Riazi A. Self-efficacy and self-management after stroke: a systematic review. Disability \& Rehabilitation. 2011;33:797-810.

43. Kendall E, Catalanoa T, Kuipersa P, Posnerb N, Buysa N, Charkera J. Recovery following stroke: The role of self-management education. Social Science and Medicine. 2007;64:735-46.

44. Marks R, Allegrante J, Lorig K. A review and synthesis of research evidence for self-efficacy-enhancing interventions for reducing chronic disability: implications for health education practice (part I). Health Promot Pract. 2005:6:37-43.

45. Aben L, BUSSCHBACH J, Ponds R, RIBBERS G. Memory self-efficacy and psychosocial factors in stroke. J Rehabil Med. 2008;40:681-3.

46. Mukaka M. A guide to appropriate use of Correlation coefficient in medical research. Malawi Med J. 2012;24:69-71.

47. Catalano T, Dickson P, Kendall E, Kuipers P, Posner T. The perceived benefits of the chronic disease self-management program among participants with stroke: A qualitative study. Aust J Prim Health. 2003;9:80-9.

48. White J, Magin P, Attia J, Pollack M, Sturm J, Levi C. Exploring poststroke mood changes in community-dwelling stroke survivors: a qualitative study. Archives of Physical Medicine \& Rehabilitation. 2008;89:1701-7.

49. Bayliss E, Steiner J, Fernald D, Crane L, Main D. Descriptions of barriers to self-care by persons with comorbid chronic diseases. Ann Fam Med. 2003;1:15-21.

50. Bayliss E, Ellis J, Steiner J. Barriers to self-management and quality-of-life outcomes in seniors with multimorbidities. Ann Fam Med. 2007;5:395-402.

51. Hilari K, Northcott S, Roy P, Marshall J, Wiggins R, Chataway J, et al. Psychological distress after stroke and aphasia: the first six months. Clin Rehabil. 2010;24:181-90.

52. Boger E, Demain S, Latter S. Stroke self-management: A focus group study to identify the factors influencing self-management following stroke. Int J Nurs Stud. 2015;52:175-87.

53. Marsden D, Quinn R, Pond N, Golledge R, Neilson C, White J, et al. A multidisciplinary group programme in rural settings for communitydwelling chronic stroke survivors and their carers: a pilot randomized controlled trial. Clin Rehabil. 2010;24:328-41.

54. Cadilhac D, Hoffmann S, Kilkenny M, Lindley R, Lalor E, Osborne R, et al. A phase II multicentered, single-blind, randomized, controlled trial of the stroke self-management program. Stroke. 2011;42:1673-9.

55. Szymczyk I, Wojtyna E, Lukas W, Kępa J, Pawlikowska T. How does gender influence the recognition of cardiovascular risk and adherence to self-care recommendations?: A study in Polish primary care. BMC Fam Pract. 2013;14:165.

56. Grzywacz J, Stoller E, Brewer-Lowry A, Bell R, Quandt S, Arcury T. Gender and health lifestyle: an in-depth exploration of self-care activities in later life. Health Education \& Behavior: The Official Publication Of The Society For Public Health Education. 2012:39:332-40.

57. Naleway A, Vollmer W, Frazier E, O'Connor E, Magid D. Gender differences in asthma management and quality of life. Journal of Asthma. 2006;43:549-52.

58. Ory M, Smith M, Ahn S, Jiang L, Lorig K, Whitelaw N. National study of chronic disease self-management: Age comparison of outcome findings. Health Educ Behav. 2014;41:34S-42s.

59. Gallant M, Spitze G, Prohaska T. Help or hindrance? How family and friends influence chronic illness self-management among older adults. Res Aging. 2007:29:375-409.

60. Jones F, Riazi A, Norris M. Self-management after stroke: time for some more questions? Disabil Rehabil. 2012;35:257-64.

61. Edelen M, Reeve B. Applying item response theory (IRT) modeling to questionnaire development, evaluation, and refinement. Qual Life Res. 2007;16:5-18.

62. Stroke [http://www.bgs.org.uk/index.php/topresources/publicationfind/ goodpractice/378-stroke]

63. Juniper E, Guyatt G, Streiner D, King D. Clinical impact versus factor analysis for quality of life questionnaire construction. J Clin Epidemiol. 1997;50(3):233-8.

64. Sijtsma K, Molenaar I. Introduction to nonparametric item response theory. London: Sage Publications; 2002.

65. Hobart J, Cano S, Zajicek J, Thompson A. Rating scales as outcome measures for clinical trials in neurology: problems, solutions, and recommendations. Lancet Neurol. 2007:6:1094-105.

\section{Submit your next manuscript to BioMed Central and take full advantage of:}

- Convenient online submission

- Thorough peer review

- No space constraints or color figure charges

- Immediate publication on acceptance

- Inclusion in PubMed, CAS, Scopus and Google Scholar

- Research which is freely available for redistribution

Submit your manuscript at www.biomedcentral.com/submit 